\title{
Analisis Perancangan Sistem Penerimaan Siswa Baru Menggunakan Framework Zachman
}

\author{
Ranggi Praharaningtyas Aji ${ }^{\mathrm{a},}$, Debby Ummul Hidayah ${ }^{\mathrm{b}}$ \\ ${ }^{a, b}$ Sistem Infromasi, Universitas Amikom Purwokerto
}

Naskah Diterima : 28 Oktober 2019; Diterima Publikasi : 4 Desember 2019

DOI : 10.21456/vol9iss2pp236-243

\begin{abstract}
The zoning system is a new perspective that has been established by the government in supporting the acceptance of new students. However, the system turned out to be one of the obstacles in education. Because it was still not standardized and the school found it difficult to explain to the community. Seeing the existing problems, researchers try to provide a solution to combat the problems in the acceptance of new students. the solution is to make an online zoning system design. The method used in this research is the Zachman framework. The results obtained defines the entity to the system to be built, including student entities, register entities, UN entities, account entities and school entities. Furthermore, several processes that become the main processes in the online registration application include account creation, registration, announcement, registration validation, account management, and reports. Whereas in network analysis there is a topology update to make students able to access online registration applications wherever and whenever. The results of this study hopefully can be used as a reference for similar research.
\end{abstract}

Keywords : System; Zonation; The Zoning System; Zachman's Framework

\begin{abstract}
Abstrak
Sistem zonasi merupakan cara pandang baru yang sudah ditetapkan oleh pemerintah dalam mendukung penerimaan peserta didik baru. Akan tetapi ternyata sistem tersebut menjadi salah satu penghambat dalam pendidikan. Karena dirasa masih belum berstandar dan pihak sekolah merasa sulit untuk menjelaskan kepada masyarakat. Melihat permasalahan yang ada, peneliti mencoba untuk memberikan suatu solusi guna memerangi permasalahan pada penerimaan peserta didik baru. Solusi tersebut yaitu membuatkan rancangan sistem zonasi online untuk penerimaan siswa baru berbasis zonasi. Metode yang digunakan dalam penelitian ini adalah kerangka kerja Zachman. Hasilnya diperoleh pendefinisian entitas terhadap sistem yang akan dibangun, meliputi entitas siswa, entitas daftar, entitas UN, entitas akun, dan entitas sekolah. Selanjutnya beberapa proses yang menjadi proses utama dalam aplikasi pendaftaran online antara lain pembuatan akun, pendaftaran, pengumuman, validasi pendaftaran, manajemen akun, dan laporan. Sedangkan pada analisis jaringan terdapat pembaharuan topologi untuk menjadikan siswa mampu melakukan akses terhadap aplikasi pendaftaran online dimanapun dan kapanpun. Adapun hasil penelitian ini dapat dijadikan rujukan bagi penelitian sejenis.
\end{abstract}

Kata kunci : Sistem; Zonasi; Sistem Zonasi; Framework Zachman

\section{Pendahuluan}

Sistem zonasi merupakaan cara baru yang ditetapkan oleh pemerintah di Indonesia guna mendukung penerimaan peserta didik baru. Sistem tersebut dibangun guna keadilan bagi semua kalangan sehingga tidak ada sistem diskriminasi (Savitri, 2019). Terkadang ada beberapa sekolah yang hanya menerima siswa dengan nilai unggul saja meskipun harus ditempuh dalam jarak yang cukup jauh dan memakan biaya transportasi. Berbeda dengan sekolah yang bisa menerima semua siswa. Sekolah tersebut akan dianggap kurang diminati dan menjadi pilihan terakhir jika tidak diterima di sekolah-sekolah unggulan.

\footnotetext{
*) Ranggi : ranggi.p.aji@ amikompurwokerto.ac.id
}

Menurut Peraturan Menteri Pendidikan dan Kebudayaan Republik Indonesia Nomor 14 Tahun 2018 Pasal 12 ayat $1 \mathrm{~b}$ menjelaskan bahwa "jarak tempat tinggal ke Sekolah sesuai dengan zonasi yang ditetapkan pemerintah daerah sesuai kewenangannya". Merujuk pada peraturan menteri tersebut maka sistem zonasi menjadi alternatif yang cukup relevan guna menghilangkan diskriminasi. Dengan adanya sistem zonasi diharapkan tidak ada lagi masyarakat yang akan memandang bahwa anaknya harus bersekolah di sekolah tertentu saja.

Sekolah menjadi salah satu jalur untuk pendidikan. Sudah sewajarnya tiap sekolah perlu untuk memberi fasilitas dan pelayanan yang baik kepada masyarakat (Ambarssari dan Setyoutami, 2014). Seperti dalam 
penerimaan siswa baru. Tiap sekolah perlu memberikan akses yang memudahkan para calon peserta didik baru untuk mendaftar. Akan tetapi, seiring berjalannya waktu muncul aturan baru yaitu adanya sistem zonasi. Berdasarkan beberapa wacana, sistem zonasi menjadi salah satu penghambat dalam pendidikan. Sistem zonasi membuat para siswa yang ingin bersekolah di sekolah pilihannya menjadi agak terhambat. Dengan terpaksa, harus memilih sekolah berdasar zonasi dan lokasinya tidak terlalu jauh dari lokasi rumah.

Hal tersebut, membuat sebagian pihak sekolah merasa kesulitan untuk menjelaskan kepada masyarakat. Di samping itu, masyarakat masih menganggap bahwa sistem zonasi dirasa belum memiliki standar khusus. Sehingga ketika mendaftarkan anaknya ke sekolah tertentu masih dapat dipertimbangkan. Berdasarkan analisis dari kondisi yang ada, maka diperlukan suatu sistem yang dapat digunakan untuk menentukan cakupan zonasi suatu sekolah sehingga pihak sekolah akan dengan mudah menjelaskan permasalahan kepada masyarakat. Selain itu akan memudahkan sekolah dalam melakukan penerimaan siswa baru sebab data akan dicatat pada satu sistem saja.

Tujuan penelitian ini adalah membuat perencanaan aplikasi pendaftaran siswa baru berbasis zonasi. Penerapan sistem informasi tanpa perencanaan yang baik dapat mengakibatkan visi dan misi sekolah menjadi tidak tercapai (Husni, 2016). Dalam penelitian ini, pemilihan model arsitektur enterprise menggunakan model kerangka kerja Zachman. Kerangka kerja Zachman adalah mendefinisikan data, aplikasi, dan teknologi dari berbagai perspektif (Surendro, 2009). Dengan melihat dari berbagai sudut pandang maka dapat dibuat rancangan aplikasi yang lebih matang.

\section{Kerangka Teori}

\subsection{Penerimaan Siswa Baru Berbasis Zonasi}

Aturan mengenai penerimaan siswa baru berbasis zonasi tertuang pada Permendikbud no 20 tahun 2019 pasal 16. Disebutkan bahwa pendaftaran siswa baru untuk dilakukan dengan 3 jalus zonasi, prestasi, dan perpindahan tugas orang tua/wali. Tujuan peraturan ini menurut Menteri Pendidikan dan Kebudayaan (Mendikbud) Muhadjir Effendy adalah untuk memastikan siswa dapat bersekolah di tempat yang dekat dan menjadikan siswa dari keluarga kurang mampu tetap dapat bersekolah di zona daerahnya (Safitri, 2019). Kuota sekolah dibagi 3 untuk masingmasing jenis pendaftaran yaitu $80 \%$ untuk zonasi, $15 \%$ untuk prestasi, dan $5 \%$ perpindahan tugas orang tua/wali. Dan setiap pendaftar hanya diperbolehkan memilih salah satu jenis pendaftaran namun dapat memilih sekolah dimanapun.

\subsection{Zachman Framework}

Kerangka kerja Zachman atau biasa disebut sebagai Zachman framework adalah salah satu kerangka kerja dari pada arsitektur enterprise yang cukup banyak diadaptasi. Kerangka kerja ini diperkenalkan oleh John A. Zachman sekitar tahun 1987. Lalu tahun 1992, dikembangkan kembali dengan tujuan sebagai penyedia struktur dasar bagi organisasi yang berguna sebagai pendukung untuk mengakses, menginterpretasi, mengembangkan, mengelola, dan melakukan perubahan terhadap suatu perangkat arsitektur SI (Slameto, Utami, \& Pangera, 2012).

Kerangka kerja Zachman membagi SI dalam 3 komponen yakni: data $\rightarrow$ proses $\rightarrow$ teknologi. Kerangka kerja ini dapat digambarkan berupa matrik 6x6 yang merupakan hasil representasi dari 2 skema klarifikasi dan arsitektur sistem 2 dimensi.

Adapun 6 perspektif sebagai baris yaitu: the planner perspective, the owner perspective, the designer perspective, the builder pers, the implementer perspective, dan the participant perspective.

Adapun untuk dimensi kedua berupa 6 kolom yaitu: What (kolom data), How (kolom fungsi), Where (kolom jaringan), Who (kolom orang), When (kolom waktu), dan Why (kolom tujuan).

\subsection{Pustaka Rujukan}

Penelitian sebelumnya pernah dilakukan dan menghasilkan suatu dokumen yang berisi perancangan terhadap penerapan teknologi informasi dan sistem informasi di kecamatan-kecamatan pada kota Samarinda terhadap sistem pelayanan publik. Dokumen tersebut merupakan tata kelola organisasi dalam kurun waktu tertentu. Metode penelitian yang digunakan dalam penelitian berupa enterprise architecture planning (Yudhana, Umar, \& Alameka, 2018). Penelitian serupa juga pernah dilakukan dan menghasilkan suatu IT blue print terhadap perancangan tata kelola sistem informasi di STMIK DCC Lampung khususnya pada sistem informasi akademik. Hasil dari perancangan menghasilkan 8 entitas, 8 sistem informasi, dan 48 kandidat aplikasi (Sukatmi, 2018).

Penelitian selanjutnya menghasilkan perancangan strategis berupa sistem informasi pada STKIP PGRI Banjarmasin (Hidayat, 2018). Metode penelitian yang digunakan adalah Enterprise Architecture Planning (EAP) dan metode Zachman. Berdasarkan penelitian tersebut menghasilkan 46 entitas yang berupa data dan 9 kandidat berupa aplikasi. Dan pada penelitian lain menghasilkan rencana strategik akan SI/TI yang berguna untuk memudahkan bagian manajemen dalam mengelola sumber daya di Universitas Pembangunan Nasional Veteran Jakarta (Solihin \& Wibisono, 2017). Adapun perancangan tersebut menggunakan pendekatan kerangka kerja Enterprise 
Architecture Planning (EAP) dan kerangka kerja Zachman.

Penelitian di STIKES Al-Irsyad Al-Islamiyyah Cilacap menghasilkan IT blue print terhadap manajemen (Lasimin, Kusrini, \& Lutfi, 2016). Perencanaan tersebut mengarah kepada penerapan ICT yang disesuaikan dengan visi kampus yaitu menjadi salah satu perguruan tinggi yang berasaskan islami dan unggul di era globalisasi. Sedangkan metode penelitian yang digunakan yakni kerangka kerja Zachman dengan EA score card. Beberapa penelitian lain juga menyatakan hal yang sama seperti penelitian yang sudah disebutkan diatas dimana penggunaan kerangka kerja EAP dan Zachman dapat digunakan membuat blue print sistem informasi (Nugroho, Yuniarno, \& Hariadi, 2019) (Zachman, 2007) (Mumtahana, Winarno, \& Sunyato, 2016 dan 2017) (Zachman, 2003) (Sugianto \& Imbar, 2019) (Syahindra, 2018) (Framework, Method, Irawan, Riady \& Sofi, 2018).

\section{Metode}

\subsection{Metode Pengumpulan Data}

Menurut (Richey \& James, 2009) menyatakan bahwa "the data researchers collected depend on the nature of their research question and hypotheses". Dalam hal ini menyatakan bahwa data menjadi salah satu faktor yang perlu diperhatikan oleh peneliti dan karena ditentukan berdasarkan perumusan masalahnya. Metode pengumpulan data berguna untuk memperoleh data-data yang dibutuhkan dalam pembuatan arsitektur enterprise ini. Beberapa metode yang digunakan yaitu:

a. Studi Pustaka

Metode ini digunakan oleh peneliti untuk memperoleh data maupun informasi dari sumber ilmiah seperti jurnal, internet, dan buku yang berkaitan dengan arsitektur enterprise.

b. Observasi

Menurut Creswell dalam (Sugiyono, 2015) menyatakan bahwa "observation is the process of gathering firsthand information by observing people and places at research site". Dalam konteks ini, metode observasi dapat dilakukan dengan mengamati orang atau proses kerja dari suatu tempat yang dilakukan pada saat penelitian. Metode observasi dalam penelitian ini digunakan untuk memperoleh data secara langsung mengenai visi, misi, serta tujuan dari beberapa sekolah khususnya sekolah menengah pertama atau sederajat.

\subsection{Alur Penelitian}

Alur penelitian menjelaskan tahapan-tahapan secara rinci dari awal sampai akhir, adalah sebagai berikut. a. Inisiasi Perencanaan

Tujuan dari pada perencanaan ini adalah membuat suatu kerangka terhadap EAP yang meliputi waktu serta idenfitikasi sumber daya dan menyeleksi anggota tim yang memiliki kualifikasi spesifik sehingga proyek dapat dikerjakan sesuai dengan tenggat waktu yang sudah direncanakan.

b. Analisis Model Bisnis

Model bisnis berarti mendefinisikan bisnis terhadap suatu enterprise. Pemodelan bisnis berguna untuk mendefinisikan arsitekturarsitektur dan perencanaan implementas.

c. Analisis Teknologi Sekarang

Tahap ini dilakukan untuk menganalisis terhadap semua sistem dan teknologi yang digunakan oleh enterprise saat ini.

d. Analisis Kebutuhan Data

Melakukan analisis kebutuhan akan data-data yang diperlukan dalam mendukung fungsi bisnis. Dalam tahap ini dilakukan identifikasi terhadap entitas, di mana masing-masing entitas terdapat atribut serta relasinya.

e. Analisis Proses

Pada tahap ini dilakukan identifikasi terhadap alur dari pada proses pengerjaan sistem.

f. Analisis Jaringan

Pada tahap ini dilakukan pendefinisian terkait arsitektur jaringan yang diperlukan untuk menjalankan sistem dan teknologi yang akan diimplementasikan.

g. Cetak Biru

Pada tahap terakhir akan dilakukan pembuatan cetak biru aplikasi yang berguna untuk mendokumentasikan semua analisis serta hasil dari pada pendefinisian dari tahap-tahap sebelumnya.

\subsection{Analisis Model Bisnis}

Permodelan bisnis dilakukan dengan menggunakan metode value chain. Model value chain berguna untuk mendeskripsikan bagaimana cara melihat suatu bisnis sebagai aktifitas yang mampu merubah masukan menjadi keluaran sehingga memiliki nilai bagi para pelanggan (Reno, 2016). Dalam value chain, didalamnya terbagi atas 2 kegiatan yaitu kegiatan Utama dan kegiatan pendukung. Pada tahap ini dilakukan analisis untuk semua kegiatan yang berhubungan dengan penerimaan siswa baru. Pada kegiatan utama terdiri dari: siswa membuat akun, siswa memilih sekolah, dan siswa mendapatkan sekolah. Sedangkan untuk kegiatan pendukung terdiri dari: manajemen sekolah, manajemen pendaftar, dan validasi pendaftar. Seluruh kegiatan ini dapat terlihat pada gambar 1 . 


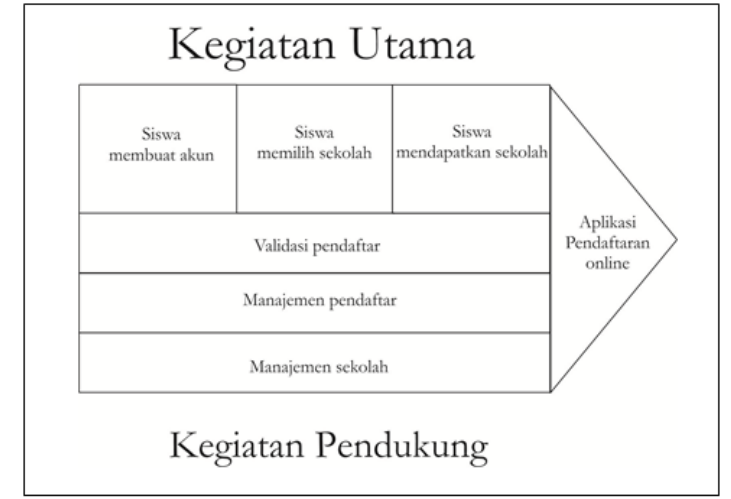

Gambar 1. Diagram value chain

\subsection{Teknologi Sekarang}

Dari analisis yang dilakukan pada dinas pendidikan aplikasi berupa: website dinas, aplikasi administrasi guru, aplikasi administrasi aset, dan aplikasi penggajian. Perangkat keras terdiri user $P C /$ Leptop 100 dan $P C$ server 1 . Perangkat lunak berupa OS windows 7-10, OS windows Server 2008, dan SQL Server. Dan Komunikasi berupa public internet, VPN (kominfo), dan LAN.

Sedangkan untuk sekolah menengah atau sederajat, teknologi yang digunakan antara lain aplikasi berupa website sekolah dan aplikasi pendataan siswa. Perangkat keras berupa user PC/Leptop 100. Perangkat lunak berupa OS windows 7-10 dan MySQL. Dan Komunikasi berupa public internet dan LAN.

\subsection{Analisis Data (What)}

Analisis terhadap arsitektur data berguna untuk melakukan identifikasi dan mendefinisikan data utama yang menjadi pendukung dalam fungsi bisnis (Asnawi, Suyanto, \& Sunyoto, 2017). Untuk mendefinisikan arsitektur data, maka data utama yang dibutuhkan perlu untuk diidentifikasi dengan cara menganalisisnya. Berikut menunjukkan entitas dan ERD yang digunakan dalam sekolah menengah pertama atau sederajat.

\section{a. Kandidat Entitas (Planer Perspective)}

Pada Tabel 1 menunjukkan beberapa kandidat entitas. Diantaranya entitas siswa (berguna untuk mendata para siswa), entitas daftar (berguna untuk memudahkan pendaftaran siswa berdasarkan zonasi), entitas UN (berguna untuk mendata hasil nilai UN (ujian nasional)), entitas akun (berguna untuk mengelola aku user), dan entitas sekolah (berguna untuk mendata sekolah).

\section{b. ERD (Owner Perspective)}

Dengan ERD maka dapat ditunjukkan dengan jelas keterkaitan antara entitas satu dengan entitas yang lainnya. Selain itu dengan penggambaran ERD maka dapat meminimalisir terjadinya redudansi data. Hubungan antara entitas UN dan entitas akun adalah satu akun dimiliki oleh satu No UN, tujuan dari dibuatnya hubungan antara 2 entitas tersebut adalah agar 1 siswa hanya akan memiliki 1 akun saja disebabkan hubungan antara entitas UN dengan entitas siswa adalah satu No UN hanya dimiliki oleh satu siswa.

\begin{tabular}{|c|c|c|}
\hline No & Entitas & Atribut \\
\hline 1 & Entitas siswa & $\begin{array}{l}\text { Id siswa, Nama, tgl lahir, umur, } \\
\text { alamat, nama orang tua }\end{array}$ \\
\hline 2 & Entitas daftar & Id daftar, validasi \\
\hline 3 & Entitas UN & No UN, nilai \\
\hline 4 & Entitas akun & No akun, User_name, password \\
\hline 5 & Entitas sekolah & Id sekolah, nama, alamat, zona \\
\hline
\end{tabular}

Selanjutnya hubungan antara entitas UN dan entitas daftar adalah setiap satu No UN mendapat satu id daftar. Berikutnya untuk entitas daftar dan entitas sekolah hubungannya adalah satu id daftar terdapat satu sekolah. Hubungan ketiga entitas ini bertujuan untuk membuat setiap 1 No UN akan mendapat 1 id daftar dengan diharuskan memiliki 1 pilihan sekolah.

Dari hubungan yang sudah dijabarkan di atas dapat disimpulkan bahwa aplikasi ini nantinya hanya akan mengijinkan 1 akun siswa hanya akan mendapat 1 id daftar dan tidak mengijinkan 1 siswa dengan No UN yang sama memiliki 2 akun atau lebih dan mendaftar lebih dari 1 kali untuk menghindarkan dari pengulangan data.

\section{c. Class Diagram (Designer Perspective)}

Class diagram menjelaskan relasi antar kelas dan penjelasan detail tiap-tiap kelas di dalam model desain dari suatu sistem (Hendini, 2016). Gambar 6 adalah class diagram berdasarkan atas ERD yang dibuat pada Gambar 2.

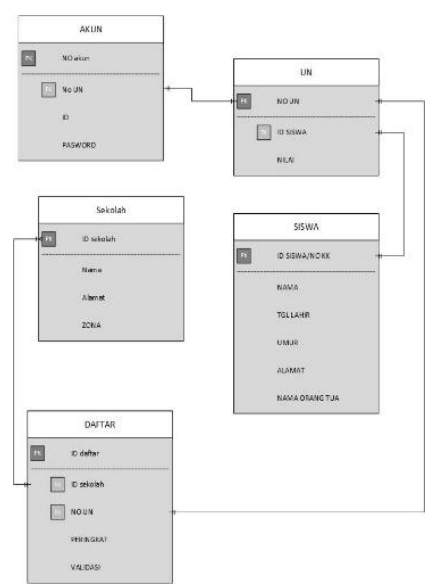

Gambar 2. Class diagram aplikasi pendaftaran online

\subsection{Analisis Proses (How)}

a. Daftar Proses (Planer Perspective)

Proses yang terjadi saat dilakukannya pendaftaran online antara lain pembuatan akun siswa, pendaftaran 
sekolah pengumuman diterima, validasi pendaftaran, manajemen akun, dan laporan.

\section{b. DFD Level 0 (Owner Perspective)}

Untuk mengetahui Owner Perspective dari proses yang diajukan pada sistem dapat digambarkan dalam gambar DFD level 0 seperti gambar 3 berikut.

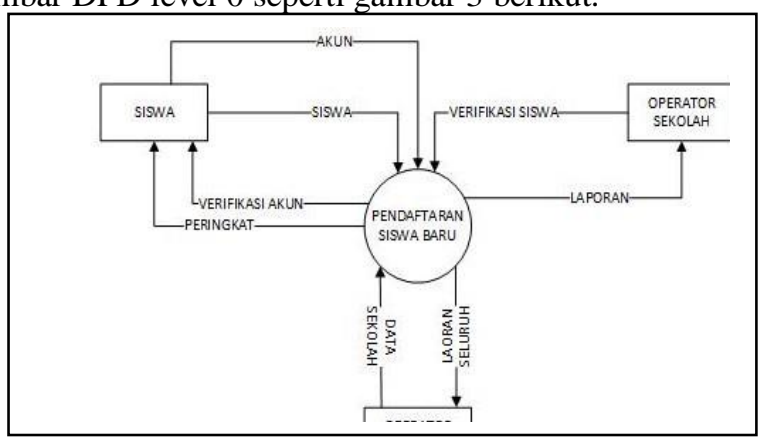

Gambar 3. Dfd level 0

\section{c. DFD Level 1 (Designer Perspective)}

Sedangkan untuk penjabaran dari setiap proses yang terjadi dari gambaran Owner Perspective dari DFD level 0 dapat dijelaskan seperti pada Gambar 8.

Proses 1 adalah "buat akun", proses ini dilakukan oleh siswa. Pada proses ini siswa akan membuat akun yang akan digunakan untuk masuk ke dalam aplikasi pendaftaran. Inputan yang diberikan siswa pada sistem adalah data akun, data siswa, dan data UN yang berfungsi sebagai validasi untuk masuk ke dalam aplikasi. Output yang dibelikan oleh sistem adalah validasi akun berupa notifikasi. Proses ini juga menyimpan data inputan ke dalam tabel sesuai entitasnya masing-masing pada database.

Proses 2 adalah "pendaftaran sekolah", proses ini dilakukan oleh siswa. Proses ini membuat siswa dapat mendaftar pada sekolah yang diinginkan. Data inputan untuk proses ini terbagi menjadi 2 yaitu data langsung dan tidak langsung. Data langsung diambil dari database secara langsung sehingga siswa tidak perlu melakukan inputan berupa data siswa dan data UN. Untuk data tidak langsung berupa pilihan sekolah yang sebelumnya telah diinputkan oleh admin dinas. Gabungan seluruh data tadi akan dimasukkan ke dalam tabel daftar. Dan output dari proses ini adalah peringkat dari siswa pada sekolah pilihannya.

Proses 3 adalah "validasi pendaftar", proses ini dilakukan oleh admin sekolah. Admin sekolah akan melakukan validasi pendaftaran setelah proses pendaftaran dinyatakan berakhir sehingga siswa dinyatakan terdaftar sebagai siswa dari sekolah pilihan setelah sebelumnya berstatus pendaftar pada sekolah pilihan. Proses ini dilakukan saat proses daftar ulang pada sekolah pilihan siswa. Input pada proses ini adalah validasi siswa baru dan memberikan output perubahan data pada table daftar.

Proses 4 adalah "manajemen akun", proses ini dilakukan oleh operator dinas. Pada proses ini operator dinas dapat melakukan manajemen akun pada tabel Akun. Proses 5 adalah "manajemen sekolah", proses ini dilakukan oleh operator dinas. Pada proses ini operator dinas akan memasukkan data sekolah yang dapat menjadi tujuan sekolah para siswa pendaftar.

Proses 6 adalah "laporan" proses ini dilakukan oleh operator dinas dan operator sekolah. Pada operator dinas laporan menampilkan seluruh data dan perubahan yang terjadi pada aplikasi untuk semua entitas pada satuan waktu, ataupun pada setiap atribut. Sedangkan untuk laporan pada operator sekolah hanya menampilkan data pada sekolahnya saja.

Proses 1 dan 2 merupakan proses utama pada aplikasi ini yang bertujuan membuat siswa dapat mendaftar pada sekolah tujuan yang diinginkan dan sistem akan langsung memberikan hasil berupa peringkat siswa tersebut pada sekolah tujuan. Proses 3 dan 6 pada sisi operator sekolah membuat sekolah mampu melakukan validasi atas pendaftaran yang dilakukan oleh siswa dan mendapatkan laporan yang sesuai dengan kebutuhan sekolah. Dan proses 4, 5, dan 6 untuk sisi operator dinas membuat dinas pendidikan dengan mudah melakukan manajemen sekolah yang dapat mengikuti pendaftaran online, melakukan manajemen atas akun yang masuk kedalam aplikasi, dan mendapatkan laporan penuh atas aktifitas pada aplikasi pendaftaran online ini.

\subsection{Analisis Jaringan (Where)}

Analisis jaringan berguna untuk mendefinisikan teknologi utama yang dibutuhkan dalam pengelolaan data aplikasi (Asnawi et al., 2017). Pada analisis jaringan memiliki 2 ketentuan yang dijadikan sebagai sandaran dalam pengimplementasian sistem. Ketentuan pertama adalah scope (untuk menentukan lokasi akses) dan enterprise model (untuk memetakan jaringan komputer).

\section{a. Penentuan Lokasi Akses (Planer Perspective)}

Lokasi akses bertujuan untuk menentukan jangkauan penggunaan dari pada sistem yang direncanakan. Akses dari pada sistem dapat dijalankan oleh siswa pada umumnya di manapun dan kapanpun karena bersifat online. Sedangkan untuk admin sekolah maka lokasi akses berada di sekolah masingmaisng. Terakhir untuk admin dinas merupakan server dan berlokasi di dinas pendidikan kota setempat.

\section{b. Konsep Jaringan (Owner Perspective)}

Pada Gambar 4 menggambarkan jaringan yang diharapkan oleh owner. Jaringan ini bertujuan agar siswa dapat mengakses dari manapun dan kapanpun. Hal tersebut juga berlaku untuk operator dinas dan sekolah. Tujuannya adalah agar tidak menjadikan alasan untuk operator harus mengakses situs website dari lokasi kerja saja. 


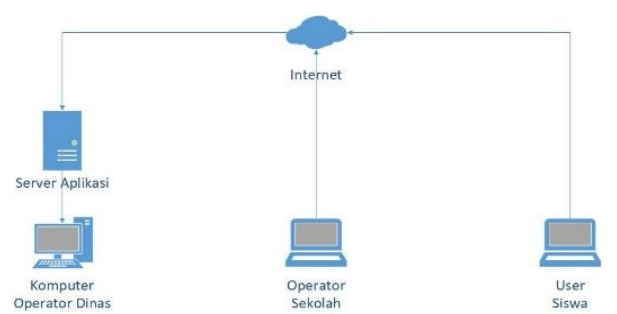

Gambar 4. Jaringan komputer

c. Pemetaan jaringan komputer (Designer Perspective)

Dalam hal ini dilakukan pemetaan jaringan komputer untuk meningkatkan kinerja dari pada sistem yang diusulkan. Topologi jaringan yang digunakan digambarkan pada gambar 5 .

Topologi jaringan ini dibuat untuk tujuan siswa dapat mengakses dari manapun dan kapanpun. Begitupun dengan admin sekolah akan mampu mengakses aplikasi secara online hal ini bertujuan agar proses pendaftaran tidak terkonsentrasi pada lokasi sekolah tujuan. Hal tersebut juga berlaku untuk operator dinas, tujuannya adalah agar tidak menjadikan alasan untuk operator harus mengakses situs website dari lokasi kerja saja.

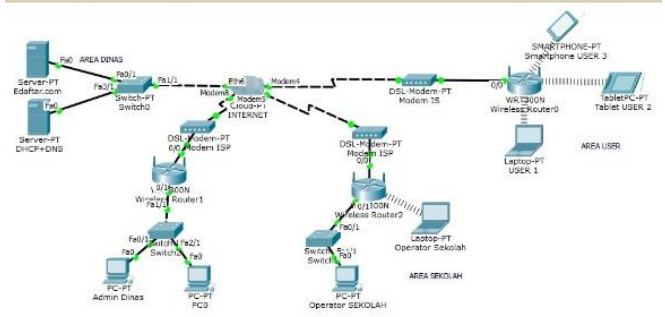

Gambar 5. Implementasi topologi jaringan

\section{Hasil dan Pembahasan}

\subsection{Blue Print}

Penelitian ini betujuan untuk membuat blueprint aplikasi pendaftaran online, maka dibuatlah blueprint. Aplikasi pendaftaran online ini terdiri atas matrik $3 \times 3$. Matrik 1.1 berupa analisis data pada sisi planer diperlihatkan pada poin 3.5.a , matrik 1.2 merupakan hasil penjabaran hubungan data dari sisi owner diperlihatkan pada poin 3.5.b. dan matrik 1.3 merupakan analisis kebutuahan dan hubungan data yang diberikan penulis sebagai hasil penjabaran dari sudut pandang planer dan owner aplikasi diperlihatkan pada poin 3.5.c.

Matrik 2.1 menunjukkan kebutuhan proses yang diharapkan diperlihatkan pada poin 3.6.a. Sedangkan matrik 2.2 merupakan gambaran proses pada aplikasi dan aliran datanya diperlihatkan pada poin 3.6.b. Matrik 2.3 merupakan detail proses pada aplikasi yang merupakan penjabaran lengkap dari penulis untuk semua proses dan aliran data pada aplikasi pendaftaran online diperlihatkan pada poin 3.6.c.
Matrik 3.1 menunjukkan rancangan lokasi akses dari aktor-aktor yang terlibat pada aplikasi pendaftaran online diperlihatkan pada poin 3.7.a. Matrik 3.2 memperlihatkan gambaran owner atas komunikasi jaringan pada aplikasi pendaftaran online diperlihatkan pada poin 3.7.b. Dan matrik 3.3 merupakan rancangan topologi jaringan yang direkomendasikan penulis untuk dibangun pada aplikasi pendaftaran online ini diperlihatkan pada poin 3.7.c.

\subsection{Uji Hasil}

Berikutnya dilakukan pengujian untuk setiap blueprint yang telah dibuat. Yang menjadi obyek pengecekan adalah hubungan antar tabel untuk kolom data. Uji proses hasil analisis untuk kolom fungsi dan uji jaringan pada kolom jaringan.

a. Uji Hubungan Antar Tabel

Pada langkah ini dilakukan pengecekan hubungan antar tabel dengan melakukan simulasi membuat database pada mysql. Query sql yang digunakan adalah "JOIN". Join dapat digunakan untuk menampilkan data pada tabel-tabel yang memiliki hubungan (Utami \& Sukrisno, 2008). Pada simulasi ini dibuatkan tabel siswa, daftar, UN, akun, dan sekolah yang terlihat pada gambar 6 .

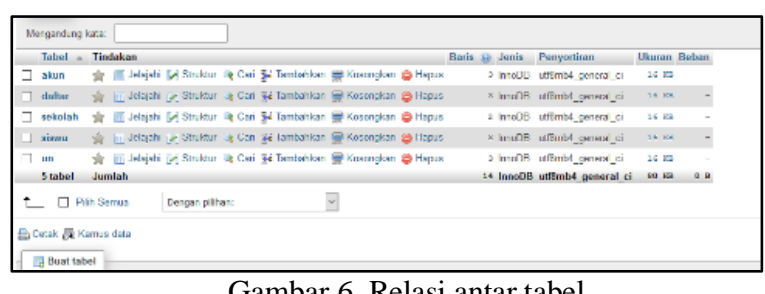

Gambar 6. Relasi antar tabel

Kemudian disimulasikan dengan menggunakan query join untuk menghasilkan tampilan nama, nilai, user_name, password, validasi ( status pendaftaran pendaftaran) dan nama sekolah tujuan. Hasil simulasi dapat terlihat pada gambar 7 .

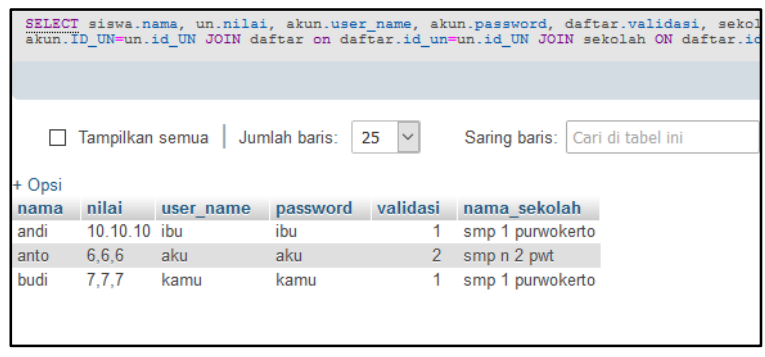

Gambar 7. Simulasi query join

Berdasarkan atas simulasi tersebut maka dapat disimpulkan bahwa semua usulan relasi tabel yang diajukan telah sesuai dan terdapat hubungan pada setiap tabel. 
b. Uji proses

Pada uji proses ini akan dicari proes pada Designer Perspective untuk dibandingkan dengan Owner Perspective. Hasil perbandingan mendapatkan kesimpulan Proses 1 dan 2 pada DFD level 1 merupakan proses utama pada aplikasi ini yang bertujuan membuat siswa dapat mendaftar pada sekolah tujuan yang diinginkan dan sistem akan langsung memberikan hasil berupa peringkat siswa tersebut pada sekolah tujuan. Proses 3 dan 6 pada sisi operator sekolah di DFD level 1 membuat sekolah mampu melakukan validasi atas pendaftaran yang dilakukan oleh siswa dan mendapatkan laporan yang sesuai dengan kebutuhan sekolah. Dan proses 4, 5, dan 6 pada DFD Level 1 disisi operator dinas membuat dinas pendidikan dengan mudah melakukan manajemen sekolah yang dapat mengikuti pendaftaran online, melakukan manajemen atas akun yang masuk ke dalam aplikasi dan mendapatkan laporan penuh atas aktifitas pada aplikasi pendaftaran online ini.

c. Uji jaringan

Pada uji jaringan ini dilakukan dengan melakukan simulasi jaringan pada aplikasi cisco paket trecer. Pada gambar 8 diperlihatkan uji akses kepada server Edaftar.com.

Berikutnya pada gambar 9 diperlihatkan uji akses situs Edaftar.com pada cisco paket trecer yang dilakukan oleh user dengan perangkat smartphone.

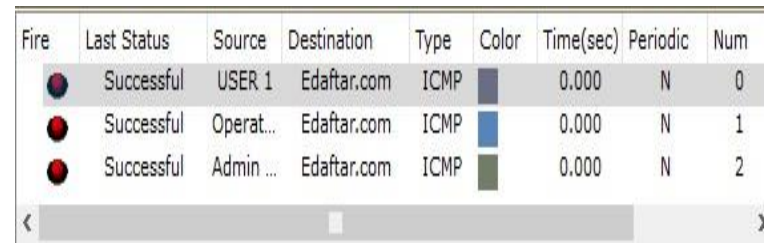

Gambar 8. Uji akses kepada server edaftar.com

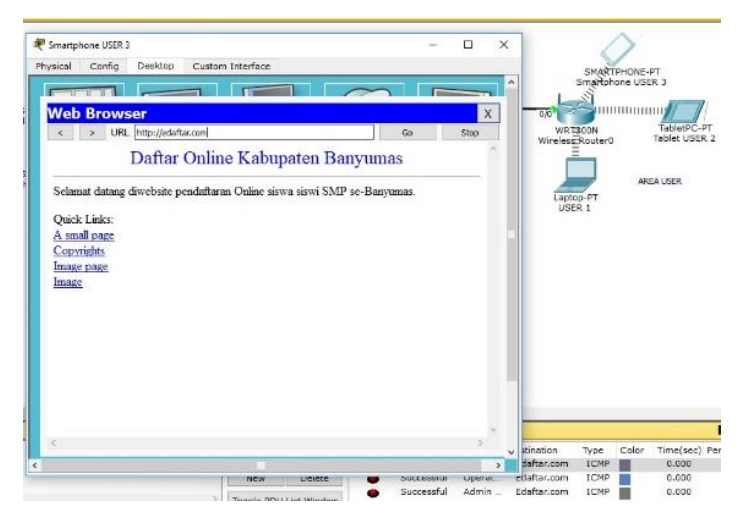

Gambar 9. Uji akses situs edaftar.com pada sisco paket tracer

Dari hasil uji jaringan ini dapat disimpulkan rangakaian topologi yang disarankan mampu mendukung kinerja user untuk dapat melakukan simulasi akses situs daftar online secara mudah tanpa perlu lagi untuk melakukan antrian disekolah tujuan. Sama halnya dengan operator dinas dan sekolah yang dapat mengakses server secara online.

\section{Kesimpulan}

Pada penelitian dihasilkan cetak biru kebutuhan teknologi pada kolom fungsi, data, dan jaringan untuk aplikasi pendaftaran online berbasis zonasi. Pada data didapati beberapa entitas yang perlu diperhatikan sebagai acuan data pada sistem pendaftaran online antara lain entitas siswa, entitas daftar, entitas UN, entitas akun, dan entitas sekolah. Selanjutnya beberapa proses yang menjadi proses utama dalam aplikasi pendaftaran online antara lain pembuatan akun, pendaftaran, serta proses pendukung yaitu validasi pendaftaran, manajemen akun, manajemen sekolah, dan laporan. Adapun pada analisis jaringan terdapat pembaharuan topologi untuk menjadikan siswa mampu melakukan akses terhadap aplikasi pendaftaran online dimanapun dan kapanpun. Pada penelitian selanjutnya diharapkan dapat dilanjutkan untuk mendapatkan analisis dari sudut pandang pengembang, programmer dan user sehingga menghasilkan aplikasi yang maksimal.

\section{Daftar Pustaka}

Ambarssari, N., dan Setyoutami, N., 2014. Perancangan blueprint sistem informasi menggunakan metodologi Enterprise Architecture Planning (EAP) pada SMAN 3 Surakarta. Jurnal Rekayasa Sistem \& Industri, 1, 141-143.

Asnawi, N., Suyanto, M., dan Sunyoto, A., 2017. Perencanaan Arsitektur enterprise sistem informasi pada STIE Dharma Iswara Madiun. Jurnal Ekonomi Dan Teknik Informatika, 4(2), 112.

Safitri, E., 2019. Mendikbud Paparkan Kelebihan Sistem Zonasi di PPDB. Retrieved July 12, 2019, from detikNews website: https://news.detik.com/berita/d-

4591338/mendikbud-paparkan-kelebihan-sistemzonasi-di-ppdb

Framework, Z., Method, A., Irawan, B.H., Riady, S. R., dan Sofi, K., 2018. Penerapan absensi kuliah berbasis QR Code dengan Modul Raspberry Pi3 menggunakan metode arsitektur zachman framework. Prosiding Seminar Nasional, Unimus, 1: 718-730.

Hendini, A., 2016. Pemodelan UML sistem informasi monitoring penjualan dan stok barang (studi kasus: distro Zhezha Pontianak). IV(2), 107-116. https://doi.org/10.2135/cropsci1983.0011183X00 2300020002x

Hidayat, M., 2018. Penyusunan rencana strategis sistem informasi STKIP PGRI Banjarmasin Menggunakan Enterprise Architecture Planning. Jurnal Teknologi Rekayasa, 2(2), 63-72. https://doi.org/10.31544/jtera.v2.i2.2017.63-72

Husni, A.F., 2016. Analisis dan pengembangan sistem informasi akademik dengan permodelan Enterprise Architecture Zachman Framework 
Pada Politeknik Jambi. Jurnal Informa Politeknik Indonusa Surakarta, 1, 1-9.

Lasimin, Kusrini, \& Lutfi, E.T., 2016. Enterprise Architecture Planning Manajemen Kampus Di STIKESAL-Irsyad Al-Islamiyyah Cilacap. Jurnal Penelitian Dan Pengabdian Kepada Masyarakat UNSIQ, (3), 219-228.

Mumtahana, H.A., Winarno, W.W., \& Sunyato, A., 2016. Perancangan arsitektur sistem informasi akademik STT Dharma Iswara Madiun dengan Zachman Framework. Jurnal IT CIDA, 2(2).

Mumtahana, H.A., Winarno, W.W., \& Sunyoto, A., 2017. Perancangan master plan sistem informasi akademik STT Dharma Iswara Madiun. Khazanah Informatika: Jurnal Ilmu Komputer Dan Informatika, 2(2), 72-84. https://doi.org/10.23917/khif.v2i2.2145

Nugroho, F., Yuniarno, E.M., \& Hariadi, M., 2019. Penerapan materi ilmu pengetahuan alam pada serious game sosialisasi mitigasi bencana berbasis model teori aktivitas dan taksonomi bloom. Jurnal Ilmu Teknologi Sistem Informasi, 5(2), 106.

Reno, S., 2016. Pengembangan model arsitektur enterprise sistem informasi menggunakan EAP pada perguruan tinggi (Studi Kasus Universitas Dehasen Bengkulu). Jurnal Media Infotama, 12(1), 70-78.

Richey, C.R., \& James, K.D., 2009. Design and Development Research. New York: Routledge.

Savitri, E., 2019. Mendikbud Paparkan Kelebihan Sistem Zonasi di PPDB.

Slameto, A.A., Utami, E., \& Pangera, A.A., 2012. Analisis dan desain arsitektur enterprise sistem informasi pelaporan kerusakan komputer dengan Zachman Framework. Jurnal Teknologi Informasi, 7(21), 37-52.
Solihin, I.P., \& Wibisono, M.B., 2017. Desain Kebijakan sistem informasi dan teknologi informasi dengan Framework Zachman pada perguruan tinggi negeri baru di Jakarta. Jurnal Rekayasa Sistem Dan Teknologi Informasi, 1(3), 266-276.

Sugianto, G., \& Imbar, R.V., 2019. Enterprise Architecture Menggunakan Zachman Framework Untuk Perusahaan X. 1, 79-93.

Sugiyono, 2015. Metode Penelitian \& Pengembangan (Research and Development). Bandung: Alfabeta.

Sukatmi, 2018. Pemanfaatan enterprise architecture planning untuk perencanaan strategis sistem informasi STMIK Dian Cipta Cendikia Kotabumi. Jurnal Informasi Dan Komputer, 6(2), 29-37.

Surendro, K., 2009. Pengembangan Rencana Induk Sistem Informasi. Bandung: Penerbit Informatika.

Syahindra, W., 2018. Perancangan Cetak Biru Teknologi Informasi Menggunakan Enterprise Architecture Planning Di Iain Curup. Informatika Sains Dan Teknologi, 3(2), 171-180.

Utami, E., dan Sukrisno, 2008. Mengoptimalkan Query pada Microsoft Sql Server. Penerbit Andi.

Yudhana, A., Umar, R., \& Alameka, F., 2018. Perancangan sistem informasi menggunakan enterprise architecture planning (studi kasus pada kecamatan di Kota Samarinda). Khazanah Informatika: Jurnal Ilmu Komputer Dan Informatika, 4(2), 114-123. https://doi.org/10.23917/khif.v4i2.7039

Zachman, J.A., 2003. The Zachman framework for enterprise architecture, primer for enterprise engineering and manufacturing. Jurnal CA Mag, 128(9), 15.

Zachman, J.A., 2007. Zachman Framework 2 Enterprise Engineering and Manufacturing. 